\title{
Geographic variability of post-disaster mental health: Case study after the 2017 flood in Bangladesh
}

\author{
Khandakar Hasan Mahmud, Raju Ahmed, Jannatun Hussna Tuya \\ Department of Geography and Environment, Jahangirnagar University, Savar, Bangladesh
}

\begin{abstract}
Every year Bangladesh faces enormous damages due to flooding. Facing these damages the Government adopts various recovery approaches. However, the psychological dimension of any disaster is generally overlooked in disaster management. Researchers have found that the spatial distribution of post-disaster mental health can help the authorities to apply recovery procedures where they are most needed. For this research, Posttraumatic Stress Checklist (PCL-5), Patient Health Questionnaire (PHQ-9) and Generalized Anxiety Disorder-7 (GAD-7) were used to estimate posttraumatic stress, major depressive disorder and anxiety following three episodes of severe floods in 2017 that affected at least 8 million people. To better understand the spatial pattern of psychological vulnerability and reach a comprehensive scenario of post-disaster mental health, Moran's $I$ was applied for spatial autocorrelation and Pearson's correlation and regression analysis for a study of the relationship between the psychological aspects. It was found that psychological vulnerability showed a spatial clustering pattern and that there was a strong positive linear relationship among psychological aspects in the study area. This research might help to adopt disaster management policies that consider the psychological dimension and spatial distribution of various psychological aspects to identify areas characterized by high vulnerability and risk so that they can be reached without delay.
\end{abstract}

Correspondence: Jannatun Hussna Tuya, Department of Geography and Environment, Jahangirnagar University, Savar, Dhaka 1342, Bangladesh.

E-mail: tuya.43@geography-juniv.edu.bd

Key words: Psychological vulnerability; floods; posttraumatic stress; spatial pattern; Bangladesh.

Received for publication: 10 May 2021.

Revision received: 8 September 2021.

Accepted for publication: 8 September 2021.

(C) Copyright: the Author(s), 2021

Licensee PAGEPress, Italy

Geospatial Health 2021; 16:1018

doi:10.4081/gh.2021.1018

This article is distributed under the terms of the Creative Commons Attribution Noncommercial License (CC BY-NC 4.0) which permits any noncommercial use, distribution, and reproduction in any medium, provided the original author(s) and source are credited.

\section{Introduction}

According to the World Health organization (WHO), disasters disrupt normal conditions of existence and generally cause a level of suffering that exceeds the capacity of adjustment of affected communities (WHO, 2002), while the United Nations Office for Disaster Risk Reduction (UNISDR) defines a disaster 'A serious disruption of the functioning of a community or a society involving widespread human, material, or environmental losses and impacts which exceeds the ability of the affected community to cope using only its own resources' (UNISDR, 2009). Indeed, human existence, environment and disaster are all intertwined, and disasters can be referred to as a complex mix of natural hazards and human reaction (Wisner et al., 2004). Disasters such as cyclones, flooding, drought periods, earthquakes etc. are often unanticipated and uncertain. Among natural hazards, floods may be the most common as they often take place annually and from the early age of civilization humans have been faced by inundation and destruction of settlements. In the ancient past, disasters were often considered as expressions of the Gods' wrath and the myth of floods is frequent in human mythologies, e.g., in the Christian Bible. However, flooding is a natural phenomenon that cannot be prevented and therefore cause large-scale human distress.

Floods and other disasters have considerable and continuous impacts on both physical and mental health of affected populations as well as on the way of daily life (Freedy and Simpson, 2007; Kim et al., 2008; Niekerk, 2011; Usman et al., 2013; Makwana, 2019; Gaillard et al., 2019; WHO, 2020). Exposed populations that are directly or indirectly affected by strong hazards usually show remarkable distress, while one type of disaster often results in different individual responses. It has been seen that vulnerability and resilience of an individual can significantly influence emotional responses (Gruebner et al., 2015), but these responses to disasters do not always appear immediately sometimes taking months to become established (Mental Health America, 2018). People generally suffer from mild to severe mental health problem in post-disaster periods according to an epidemiological projection by WHO (2019). WHO estimates that 20 to $40 \%$ of people involved develop mild psychological symptoms, whereas as many as 30 to $50 \%$ may suffer from moderate to severe psychological mental health problems (WHO, 2019). Norris et al. (2002) conclude that 22 to $77 \%$ people suffer post-traumatic stress, anxiety and depression after major natural disasters. In addition, psychological conditions during and after a hazard can positively influence hazard impacts that sometimes get worse over time (Norris, et al., 2002; McFarlane and Williams, 2012; Makwana, 2019). It is often thought that people with psychiatric disorders and severe mood disorders are more vulnerable and less able than others to cope effectively with disaster related stressors (Jankowski, 2016). However, it is an obvious fact that any people affected by disasters will suffer from long-term trauma, often developing poor mental health conditions afterwards 
(Freedy and Simson, 2007; Gruebner et al., 2015; WHO, 2017).

Moreover, people in low- and middle-income countries react mentally more adversely during natural hazards, and the psychological recovery process is slower than in developed countries (Norris et al., 2002). Southeast Asia is particularly vulnerable to natural disasters with examples including first-page news, such as the 2007 Sidr cyclone in Bangladesh, the 2008 Nargis cyclone in Mynamar and the great earthquake of 2015 in Nepal (ADB, 2019; Gonzales, 2019). Besides, flooding is a recurring phenomenon in Bangladesh. Still, the mental trauma and long-term effects of the affected communities during these and other disasters have been overlooked.

Disaster database and statistics of Bangladesh show that the country has witnessed a severe flood event about every 7 years and a catastrophic one with 33 to 50 years interval. Whenever it occurs, people suffer and the government cannot easily deal with the damages caused with respect to agriculture, people's livelihood, environment and infrastructures, such as roads, embankment, buildings, etc. along with health conditions (both physical and mental). Flooding affects exposed populations in a significant way and the economic damages caused have medium- to long term-impact on social relationships, individual well-being and physical as well as mental health (Alderman et al., 2015). It is also evident that those in a poor mental state are more vulnerable during disasters and therefore unable to overcome the situation. Moreover, studies of psychological vulnerability are important for the recovery from disastrous situations. Because psychologically strong people as well a community as a whole can be able to build on the community resilience rather than relying on outside support, e.g., in the United Kingdom mental health problems along with other chronic disabilities can cause $80 \%$ of the estimated disability in adjusting life after disasters as shown by a study covering the period 2003 to 2008 (Fewtrell and Kay, 2007). The field of hazard and disaster studies mental health has not received interest from researchers until recently. Researchers have started to explore the determinants that are directly responsible for poor mental health conditions including posttraumatic stress disorder (PTSD), major depressive disorder and generalized anxiety disorder in the post disaster period (Ginexi et al., 2000; Agaibi and Wilson, 2005; Kar and Bastia, 2006; Ursano, et al., 2006; Goldmann and Galea, 2014). Till now, researchers have identified and documented various vulnerability factors which impact mental wellbeing negatively (Rodriguez-Llanes et al., 2013). Such vulnerable factors are high-exposure levels, poor socio-economic conditions, inconsistent demographic structure and frequent traumatic incidents. Moreover, several research results to date show that psychological distress after disasters varies across geographic space (Curtis et al., 2007; DiMaggio et al., 2010; Maghrabi, 2012; Gruebner et al., 2015). Often low levels of psychological distress are centralized in specific geographic areas, and researchers have shown potential use of geospatial analysis to understand the distribution pattern of psychological distress, e.g., the spatial pattern of psychological vulnerability in Gobindaganj Upazila after the 2017 flood.

In this research, we have considered two hypotheses; the null hypothesis that there is no spatial pattern of psychological vulnerability in the study area and the alternative hypothesis that there is a spatial pattern of psychological vulnerability that can be used to direct authority as to where the recovery process should begin, and which geographic areas have the greatest need for post-disaster services. The two objectives were: i) to measure the psychological vulnerability and analyse spatial pattern using spatial statistics; and ii) to investigate the geographical variability of psychological vulnerability in the study area.

\section{Materials and methods}

We chose to present a case study since this approach gathers both qualitative and quantitative data producing a more vigorous picture of the consequences due to hazards in the study area considering the space dimension. In addition, case-based research provides in-depth descriptions of a process or phenomenon within a bounded system or settings as pointed out by Weiss (1995) and more recently by Marshall and Rossman (2010).

\section{Study area selection}

In 2017, three episodes of severe floods affected large areas of Bangladesh that caused loss of lives and affected the livelihoods of at least 8 million people. The northern part of the country was hit by heavy rains in August, which caused rivers to overflow resulting in severe floods in 31 out of the country's 64 districts (Prothom Alo, 2017; DhakaTribune, 2017; NIRAPAD, 2017). In Gaibandha District, Gobindaganj Upazila is one of those Upazilas that faced massive damage due to the 2017 flood (NDRCC, 2017) (Figure 1). The unions (the smallest rural, administrative units) of Sapmara, Gumaniganj, Gobindaganj Pourashava, Rakhal Baruz, Darbasta, Taluk Kanupur and Nakaihat were the most affected ones in Gobindaganj Upazila. These unions were mostly affected when by the river Karotoya on 20 August 2017 reached $21.41 \mathrm{~m}$ above the Public Works Datum (PWD), a measure related to the mean sea level and used to indicate when danger levels are reached. With a danger level for this river declared at $20.15 \mathrm{~m}$ PWD (1.08 m above its normal level), this was $1.26 \mathrm{~m}$ above the danger level (Davies, 2017). Several ox-bow lakes (a U-shaped water body formed when a meandering part of a river is cut off), channel placements, low-lying areas near the river, damaged embankment and settlements outside of the embankment greatly influenced the damages. For such reason, Gobindagonj Upazilla (Figure 1) was considered for this study.

\section{Sampling}

We stratified the sampling procedures into two layers. First, considering the nature of this research, a river of Gobindaganj Upazila was considered as the major geographic variable and based on the location of that river 56 sampling point were determined (Figure 2). Among those points, several were selected within 2-km distance along both sides of the river. For the points across the river, perpendicular lines were drawn through each point along the river and further two sub-points for each base point selected with a 1-km interval. Some places were intentionally avoided to prevent the results from overlapping. Secondly, stratified random samplings were considered to determine the possible points of sample for data collection, Stratified Random sampling, also sometimes called proportional or quota random sampling, involves dividing the population into homogeneous subgroups and then taking a sample random in subgroups (Trochim, 2018). From each point we randomly selected a number of representatives for different stakeholders for a questionnaire survey. In total, 106 males and females were studied.

\section{Study variables and tools}

For the study of psychological vulnerability of Gobindaganj Upazila after 2017 flood, both primary data and secondary data were used to conduct this research work. Population data and satellite imageries were the secondary data and those were collected from Bangladesh Bureau of Statistics (BBS) and Google Earth, respectively. To achieve the aim of this research work, the questionnaire 
survey and spatial statistical analysis were conducted. In the first phase, the individual's behavioural symptoms (e.g., suicidal tendency, low energy, etc.) and physical symptoms (e.g., insomnia, headache, etc.) were considered and when collecting the data for PTSD and the depression and anxiety levels from the study area using the following different tools.

\section{Posttraumatic stress checklist for posttraumatic stress disorder}

Posttraumatic stress disorder can be measured by the PCL-5, which consists of 20 questions that assesses the symptoms of PTSD developed by Weathers et al. in 2013 and used by Blevins et al. (2015), the National Center for PTSD (2019) and others). In the

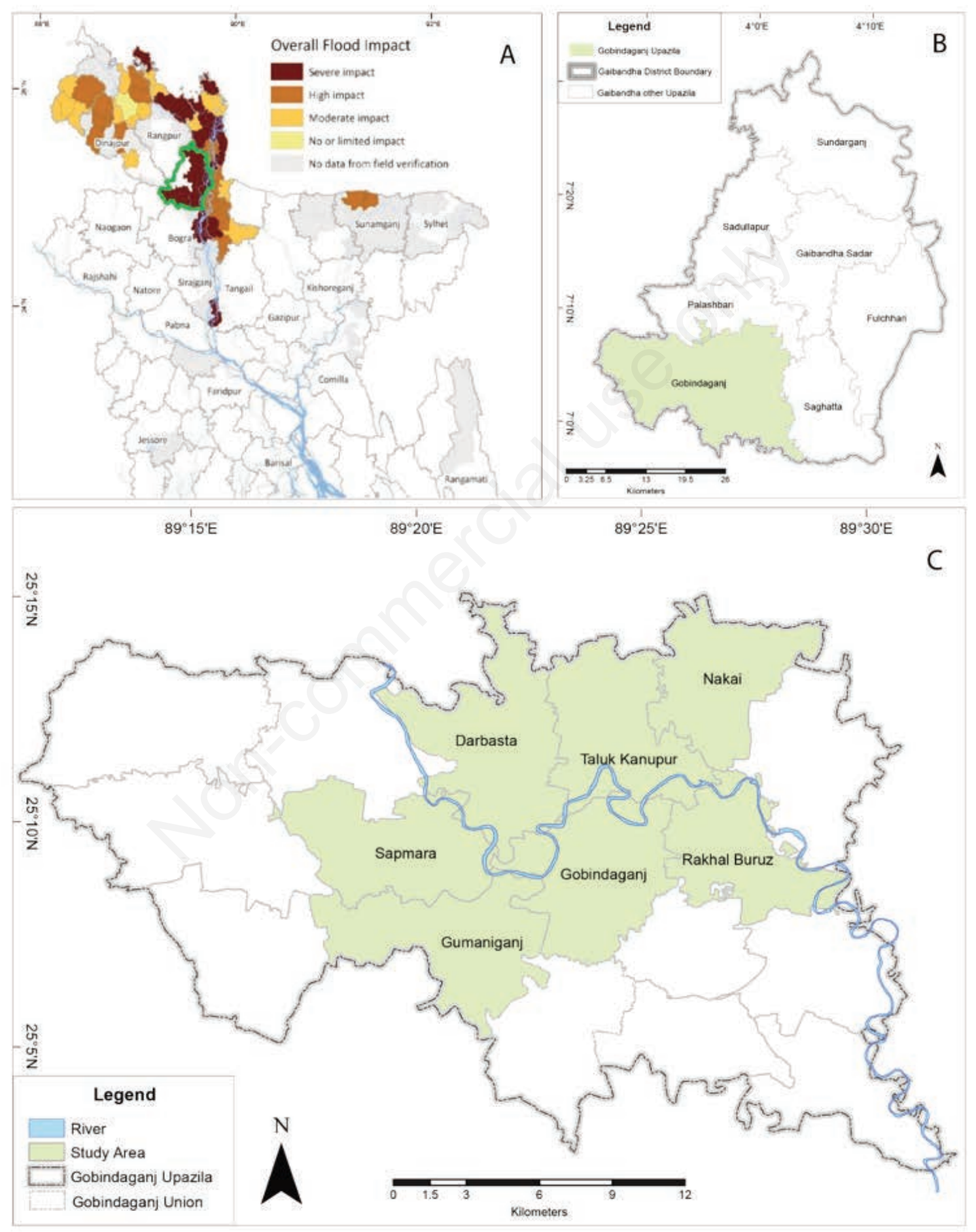

Figure 1. Study area. A) Green area depicts the severely impacted Gaibandha District (source: NDRCC, 2017); B) Gobindaganj Upazila highlighted in the Gaibandha District Map; C) Study area showed in Gobindaganj Upazila Map. 
Diagnostic and Statistical Manual of Mental Disorder- $4^{\text {th }}$ edition (DSM-4), PCL has three versions: for the military (PCL-M), for civilians (PCL-C) and for specific use (PCL-S). Each of them uses a small degree of different instructions and wording. PCL-5 is most similar to the PCL-S version and often considered the 'golden standard' and reliable tools for screening posttraumatic stress disorder (Blevins, et al., 2015; Osório, et al., 2016; Ibrahim, et al., 2018; Magowan, 2018; American Psychological Association, 2018; Fung, et al., 2019; National Center for PTSD, 2019). It categorizes the posttraumatic stress into four level ranging from 0 to 80 .

\section{The generalized anxiety disorder for anxiety disorder}

GAD-7 is a seven-item self-report anxiety questionnaire developed by Pfizer Inc. (Williams, 2014). GAD-7 was originally developed as a measure to identify the presence of generalized anxiety disorder. It is considered as helpful and reliable tools for the identification of other common anxiety disorders in clinical practice, such as- panic disorder, social anxiety disorder (Kroenke et al., 2007).

\section{Patient health questionnaire-9 for depression}

PHQ-9 is a module of a larger Patient Health Questionnaire, an assessment that patients can complete to screen for mental health conditions developed by Pfizer Inc. It assesses the symptoms of depression identified in DSM-4 by 9 short, general questions and then categorizes the results into five different level of depression. The value of PHQ-9 varies from 0 to 27 and considerably outstanding for diagnose depression (Kroenke, et al., 2001; Rathore, et al., 2014; Rancans, et al., 2018; Maroufizadeh, et al., 2019).

A well-structured questionnaire was developed following PCL-
5, GAD-7 and PHQ-9 along with other general community level questions and used as survey instrument for the data collection. We compiled the answers of the respondents in order to understand how the people reacted as a whole psychologically and estimated their vulnerability level based on the individual scale. The participants were also asked to state their conditions immediately after the flood.

In the second phase, the collected psychological vulnerability data were spatially analysed applying geographical information systems (GIS) with Moran's I for spatial autocorrelation. In addition, Pearson correlation coefficient was calculated, and regression analysis carried out using SPSS software. Besides, GIS and remote sensing was used throughout the whole study for georeferencing, digitizing and map production.

\section{Questionnaires}

\section{Posttraumatic stress disorder, generalized anxiety disorder and major depressive disorder calculations}

Three questionnaires were used as surveying tools with different scale and calculation procedures as described in Table 1. We followed the default calculation procedures for categorize the value according to the scale for further analysis.

\section{Psychological vulnerability}

As mentioned previously, posttraumatic stress, anxiety and depression were assessed and measured by PCL-5, GAD-7 and PHQ-9, respectively. These three tools have different scales of measurement, so we converted the measurement scale into a generalized scale to bring all three aspects into one generalized analy-

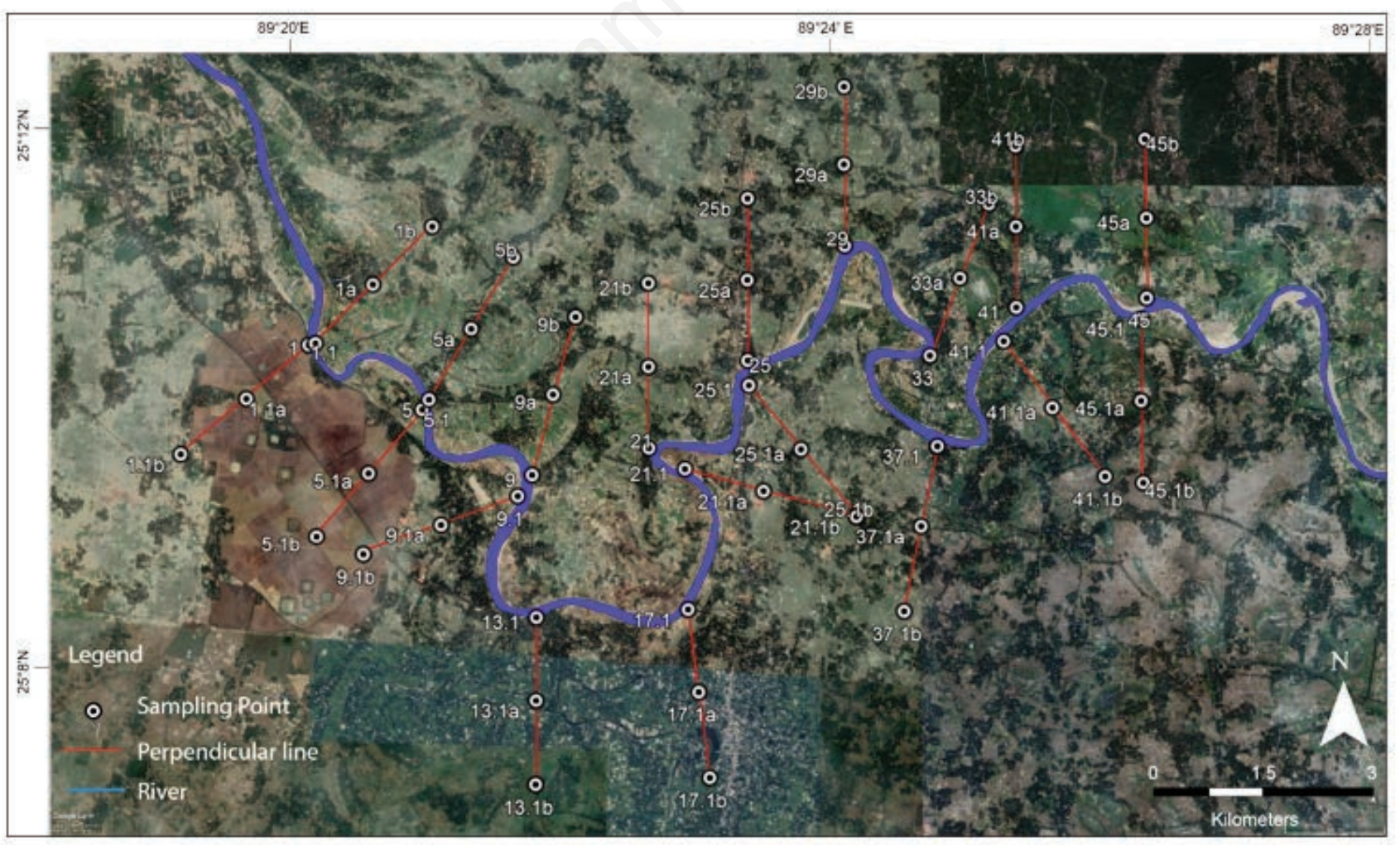

Figure 2. Sampling points. 
sis platform to be able to compare the level of their psychological vulnerability. The following formula was used for the conversion of the PTSD, depression and anxiety:

$$
V_{P A}=\frac{V_{i}}{V_{H}}
$$

where $\mathrm{V}_{\mathrm{PA}}$ represents the psychological aspect considered in this study; $V_{i}$ the value obtained by an individual for PTSD/anxiety/depression; and $\mathrm{V}_{\mathrm{H}}$ the highest value of the scale used in the PCL-5/GAD-7/PHQ-9 calculations.

\section{Statistical analysis}

Reflecting the idea of Tobler's first law of geography (1970) which states that 'Everything is related to everything else, but near things are more related than distant things', spatial autocorrelation measures the connections and degree of connectedness of close objects compared to other close objects.

Spatial patterns refer to a perceptual composition, position and organization of objects which also consider the space between those objects. Depending on the objects' arrangement and position, patterns can easily be identified whether it is a cluster linearity, i.e. in the X-Y plane, or a spatial pattern with a visible regularity. However, when potential patterns are not easily discerned, spatial statistics is required (Bass, 2015). Spatial autocorrelation is multidirectional and multi-dimensional, making it useful for finding patterns in complicated datasets. While other correlation coefficients measure correlations spanning from perfect to none, Moran's $I$ is slightly different (due to the more complex, spatial calculations) varying from -1 (perfect dispersion) over 0 (no autocorrelation at all, i.e. perfect randomness) to +1 which indicates (perfect clustering of similar values, i.e. total opposition to dispersion). Using the formula below, Moran's $I$ of spatial autocorrelation can identify whether similar characteristics are clustered or randomly distributed in space (ESRI, 2005):

$$
I=\frac{\mathrm{n}}{\mathrm{S}_{\mathrm{o}}} \frac{\sum_{i=1}^{n} \sum_{j=1}^{n} w_{i, j} z_{i} z_{j}}{\sum_{i=1}^{n} z_{i}^{2}}
$$

where $z_{i}$ is the deviation of an attribute of feature $i$ from its mean; $w_{i, j}$ the spatial weight difference between features $i$ and $j$; n the total number of features; and $S_{o}$ the aggregate of all the spatial weights.

Regression analysis was conducted in SPSS software in order to observe the relationship pattern among the psychological aspects considered. The following formulas were used for the correlation coefficient:

$$
r=\frac{\sum(x-\bar{x})(y-\bar{y})}{\sqrt{\sum(x-\bar{x})^{2}(y-\bar{y})^{2}}}
$$

where R represents Pearson's correlation coefficient; $x$ the mean of the $x$ variables; and $y$ mean of the $y$ variables.

$$
\mathrm{y}=\mathrm{A}+\mathrm{Bx}
$$

where

$A=\frac{\left(\sum y\right)\left(\sum x^{2}\right)-\left(\sum x\right)\left(\sum x y\right)}{n\left(\sum x^{2}\right)-\left(\sum x\right)^{2}}$

$B=\frac{n\left(\sum x y\right)-\left(\sum x\right)\left(\sum y\right)}{n\left(\sum x^{2}\right)-\left(\sum x\right)^{2}}$

The regression formula depicts how the dependent variable will change when one or more independent variables change due to factors. In the regression analysis, formula, $Y$ is the dependent

\begin{tabular}{|c|c|c|c|c|}
\hline \multirow[t]{2}{*}{ Mental health condition } & \multirow[t]{2}{*}{ Measuring tool } & \multicolumn{2}{|c|}{ Scale } & \multirow[t]{2}{*}{ Collected value (mean) } \\
\hline & & Score & Category & \\
\hline Post-traumatic stress disorder(PSTD) & Post-traumatic stress Checklist (PCL-5) & $\begin{array}{c}0-20 \\
20-40 \\
40-60 \\
60-80\end{array}$ & $\begin{array}{c}\text { Mild } \\
\text { Moderate } \\
\text { Severe } \\
\text { Extreme }\end{array}$ & $\begin{array}{l}\text { Maximum: } 62.5 \\
\text { Minimum: } 24.5\end{array}$ \\
\hline Generalized anxiety disorder (GAD) & Generalized anxiety disorder-7 (GAD- 7) & $\begin{array}{c}5-9 \\
10-14 \\
15-21\end{array}$ & $\begin{array}{c}\text { Mild } \\
\text { Moderate } \\
\text { Severe }\end{array}$ & $\begin{array}{l}\text { Maximum: } 17 \\
\text { Minimum: } 6\end{array}$ \\
\hline Major depressive disorder (MDD) & Patient health questionnaire (PHQ-9) & $\begin{array}{c}0-4 \\
5-9 \\
10-14 \\
15-19 \\
\geq 20\end{array}$ & $\begin{array}{l}\text { Normal range } \\
\text { Minimal } \\
\text { Mild } \\
\text { Moderate } \\
\text { Severe }\end{array}$ & $\begin{array}{c}\text { Maximum: } 18.5 \\
\text { Minimum: } 4.5\end{array}$ \\
\hline
\end{tabular}
variable; $\mathrm{X}$ is the independent variable; $A$ is the intercept and $B$ is the slope.

Table 1. Scales used for the questionnaires. 


\section{Results}

\section{Spatial distribution of posttraumatic stress disorder}

From a general viewpoint of Figure 3, the number of extreme PSTD cases was relatively low (5.7\%), and they were found at the adjacent points to the river. Most cases with a moderate PSTD level were found $2 \mathrm{~km}$ away from the river and only a few of them $(3.8 \%)$ around $1 \mathrm{~km}$ from the river, However, also some with severe-level PSTD were found between these two categories. Importantly, all cases did not follw this scenariao as the topography in some places included ox-bow lakes with very low-lying areas and thus created highly vulnerable conditions resulting in the presence of cases with higher levels of higher-level PSTD unrelated to the distance from the river (see maps 3, 4 and 5). These cases were found in the south-western part of Darbasta Union and they were labeled 'exceptional' as they were due to various local, micro-scale geographic variables.

We also found a difference in the level of post-traumatic stress between males and females. The PTSD score was significantly higher in women; e.g., in the study community, $19.8 \%$ of the males and $15.1 \%$ of the females showed moderate levels of PTSD, while $28.3 \%$ of the males and $31.1 \%$ of the females showed severe-level PTSD. Only $1.9 \%$ of the males showed extreme-level PTSD, whereas the figure for the females was as high as $3.8 \%$.

\section{Spatial distribution of generalized anxiety disorder}

In Figure 4, GAD cases with severe anxiety (24.52\%) were found at points adjacent to the river and several exceptional cases in
Darbasta Union and in the western part of Gobindaganj. Moderatelevel GAD cases $(49.06 \%)$ were also found at points adjacent to the river, but $1 \mathrm{~km}$ and also $2 \mathrm{~km}$ away. As for the PTSD cased, several 'exceptional' cases were found throughout the whole study area. Besides, mild-level GAD cases $(26.41 \%)$ were found $2 \mathrm{~km}$ far away from the river and some 'exceptional' cases were also detected there. As the case for PTSD and MDD, the GAD values also varied between the male and female groups. Females tend to have higher level of anxiety than males; e.g., $17.9 \%$ of them showed severe-level $\mathrm{GAD}$, whereas only $8.5 \%$ of the males reacted with severe-level anxiety. Whereas $25.5 \%$ of the males showed moderate levels of anxiety, only $22.6 \%$ of the females did so. With respect to mild anxiety, $9.4 \%$ of the females showed these symptoms, while as many as $16.0 \%$ of the men reacted this way.

\section{Spatial distribution of major depressive disorder}

Figure 5 shows that normal and minimal depression cases were found as far as $2 \mathrm{~km}$ from the river. Moderate-level MDD cases were found at adjacent points to the river and a few 'exceptional' cases were seen in the south-western part of Darbasta Union and the western part of Gobindaganj, while mild forms occurred in the area $1 \mathrm{~km}$ from the river and also in the southern part of Taluk Kanupur Union. In addition, there were differences in the level of MDD between males and females. The score was significantly higher in women, e.g., moderate MDD cases were found in $12.3 \%$ of the males, whereas this affection reached $15.1 \%$ in the females. Besides, $22.6 \%$ of the males and $24.5 \%$ of the females showed mild-level MDD. On the other hand, $13.2 \%$ of the males and $10.4 \%$ of the females suffered from minimal-level MDD and $1.9 \%$ of the males showed normal MDD levels.

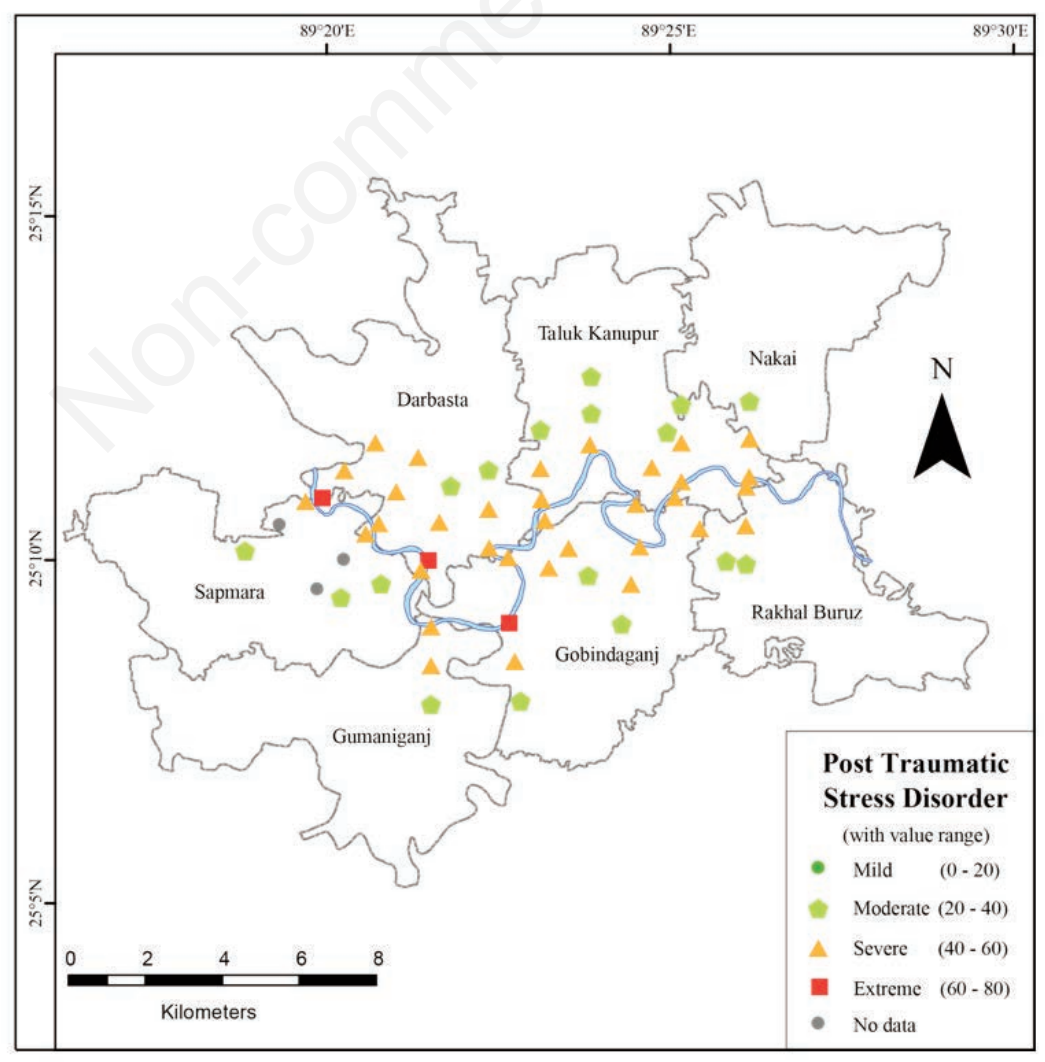

Figure 3. Spatial distribution of post-traumatic stress disorder in the study area. 


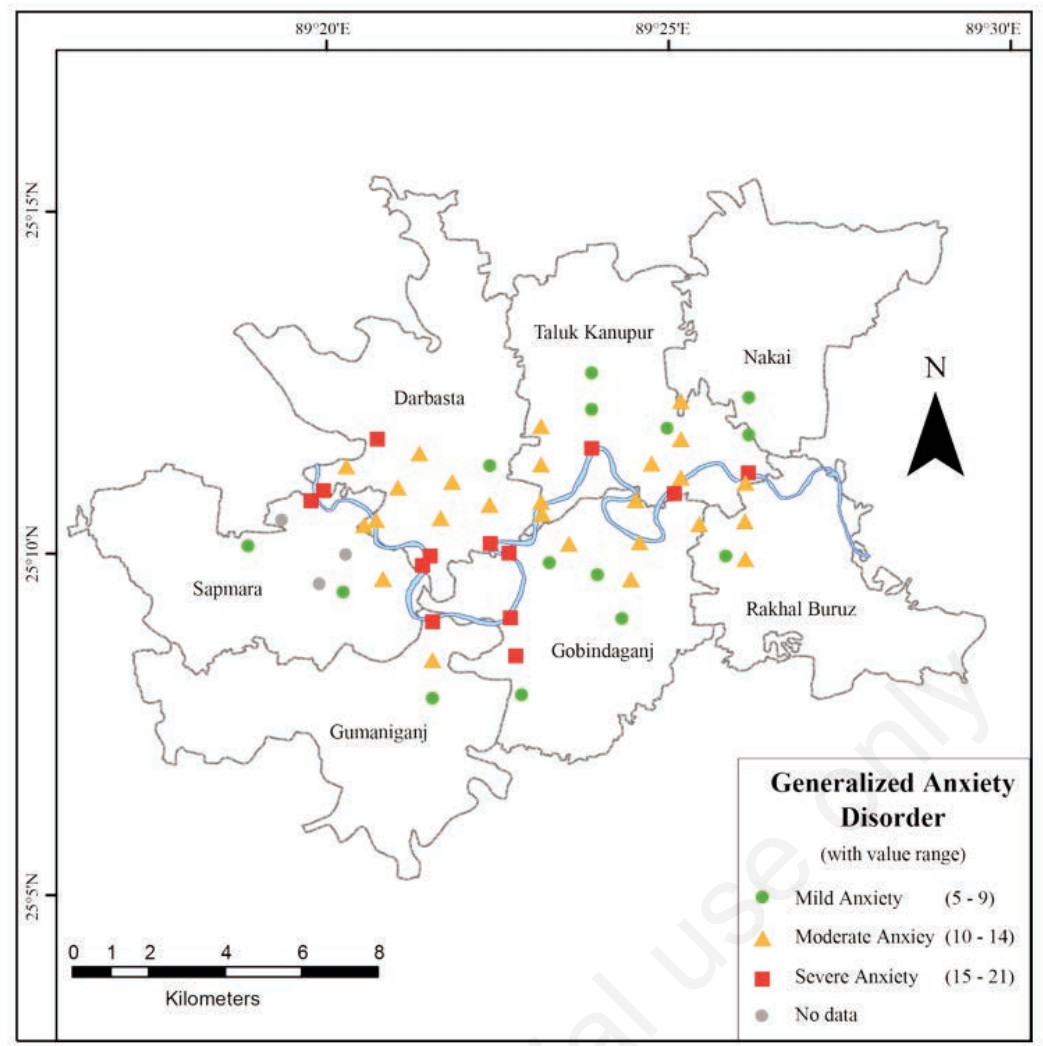

Figure 4. Spatial distribution of generalized anxiety disorder in the study area.

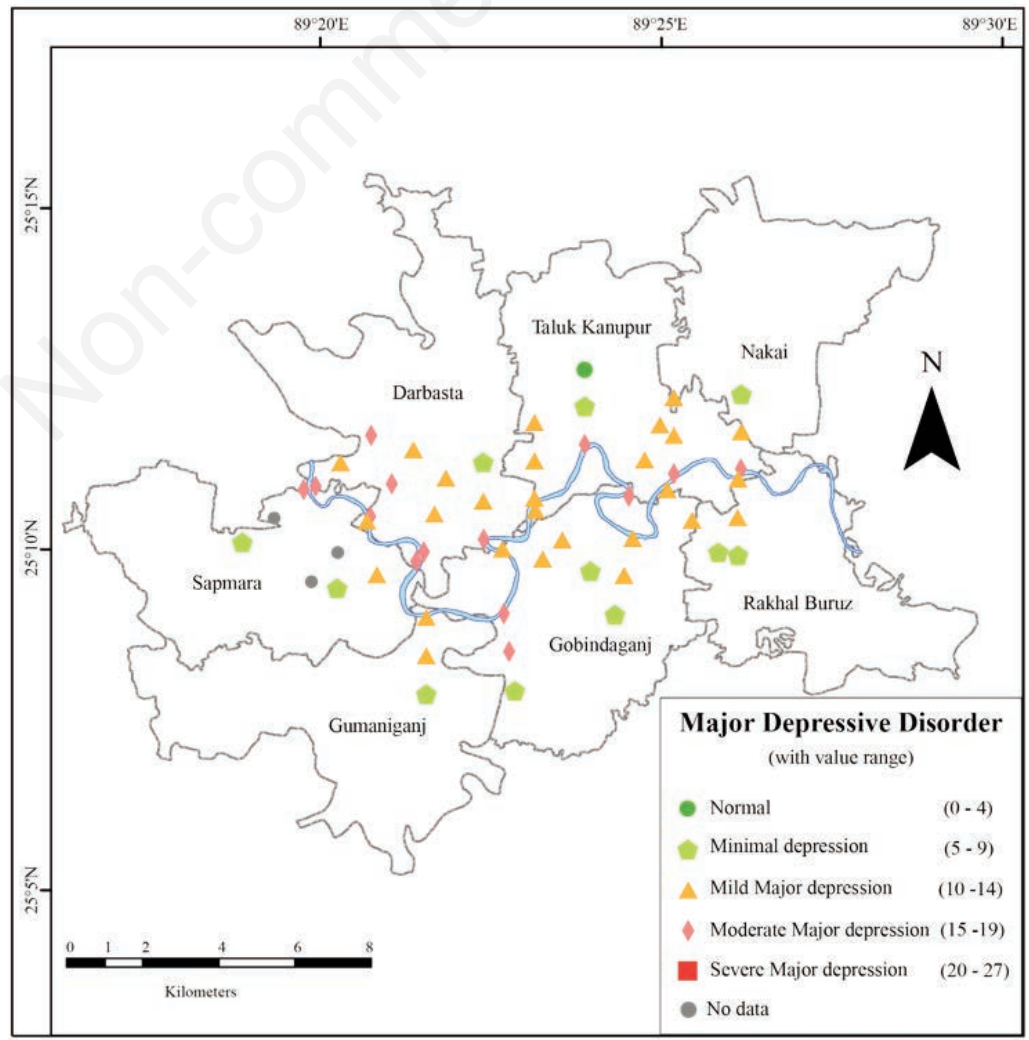

Figure 5. Spatial distribution of major depressive disorder in the study area. 


\section{Autocorrelation}

Moran's $I$ autocorrelation results are presented in Table 2, where it can be seen that the values for PTSD, GAD and MDD were all positive and greater than 0 , which indicates perfect clustering of similar values. On the other hand, the positive $\mathrm{Z}$-scores indicate that data were spatially clustered in some way. The P-values, considered as proof against the null hypothesis, were equal and less than 0.0002 which indicate a likelihood of less than $0.02 \%$ that the clustered pattern emanating from Moran's $I$ and Z-scoring could have been the result of random chance. Thus, the mental health conditions of the community studied were obviously clustered, and we noted that the high values of PTSD, GAD and MDD near the river gradually decreased with increased distance from the river.

\section{Level of the psychological vulnerability in the study area as a whole}

As mentioned previously, the PTSD, GAD and MDD data values were normalized by converting them into a joint scale. Based on this approach, Table 3 presents the psychological vulnerability level of the study community. Since the three aspects of the psychological state (stress, anxiety, depression) can be presented jointly after normalizing the values by converting the values at each sample location, the values of each point of the popular vulnerability level can be mapped and presented graphically (Figure 6). In the map, every point value from first row (the orange line), every point from second row (the blue line) and every point from the third raw (the green line) can be visualized. Besides, these values have plotted in triangles. The same procedures were executed to develop the same triangle for both the southern and the northern points. Thus, after plotting the normalized value in triangle anyone

Table 2. Summary of the autocorrelations found in the study area.

\begin{tabular}{lccc} 
Statistic & PISD & GAD & MDD \\
Moran's I & 0.65 & 0.66 & 0.64 \\
Z-score & 3.84 & 3.82 & 3.71 \\
\hline P-value & $\leq 0.0001$ & $\leq 0.0001$ & $\leq 0.0002$ \\
\hline
\end{tabular}

PTSD, posttraumatic stress disorder; GAD, generalized anxiety disorder; MDD, major depressive disorder.
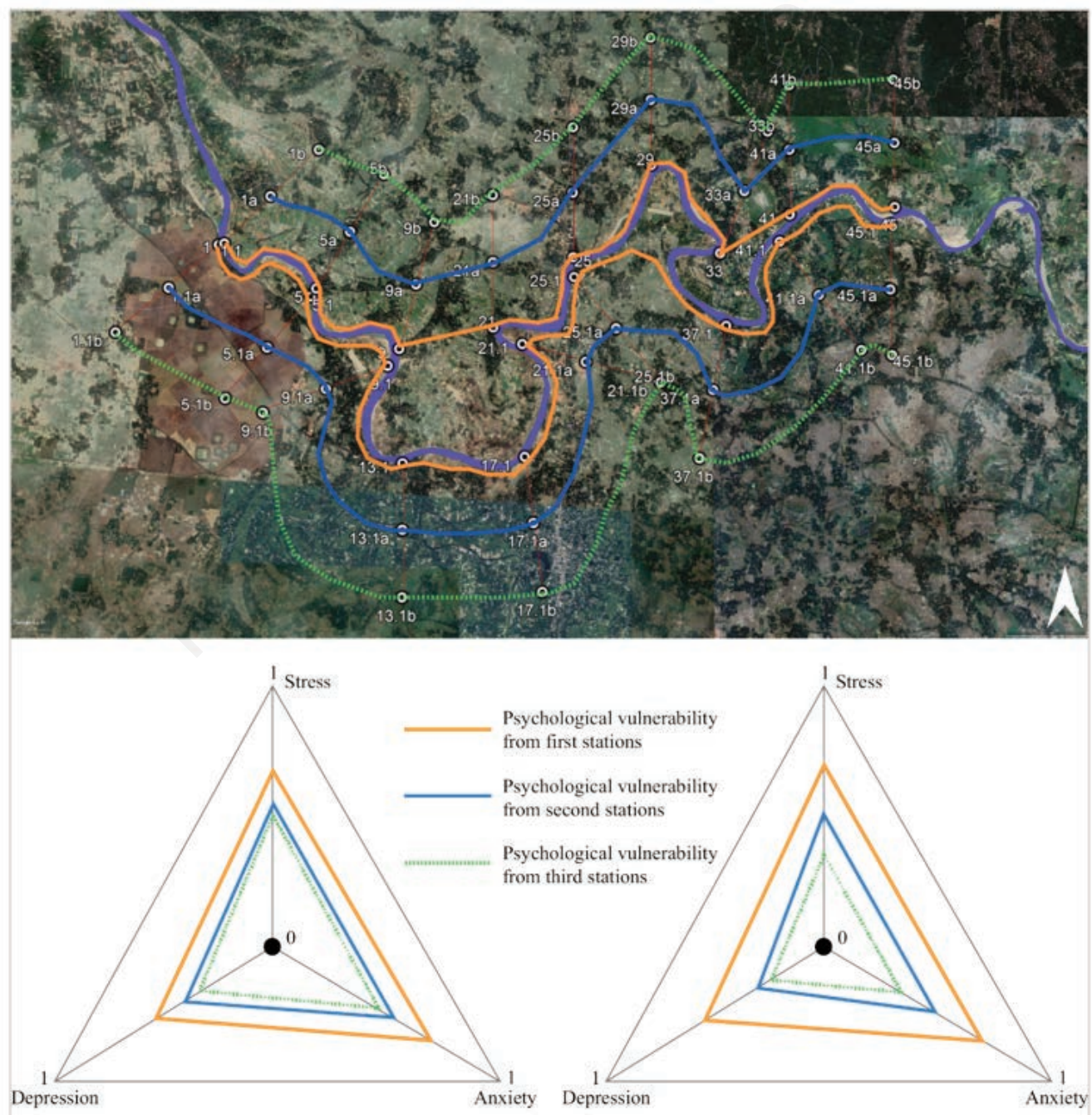

Level of Psychological vulnerability from north points Level of Psychological vulnerability from south points

Figure 6. Level of psychological vulnerability of the study area. 
can get a holistic understanding of psychological vulnerability of the study community.

These triangles clearly represent the psychological vulnerability level of the community. From the figure it can be seen that the higher level of psychological vulnerability was localized at the adjacent areas of the river and decreased with the distance further away.

The Pearson correlation values are presented in Table 4, showing that the considered three aspects of psychology (post-traumatic stress, anxiety and depression) share a strong positive linear relationship in the studied community. It can be seen that an increase in one aspect of psychology can promote the other two aspects as conveyed by the marked lines.

A simple linear regression was calculated to predict the relationship of three psychological aspects (Table 5). We first calculated the MDD based on the PTSD finding a significant regression equation $(F(1,54)=435.161,<0.000)$, with an $\mathrm{R}^{2}$ of 0.890 . This value indicates the proportion of variance in the dependent variable (depression) which can be explained by the independent variables (stress). This is an overall measure of the strength of association and does not reflect the extent to which any particular independent variable is associated with the dependent variable. SE is the standard deviation of the error term and the square root of the mean square.

\section{Discussion}

When a natural event or a disaster strikes, the effects on human life and the physical damages caused are spatially delineated. As a result, people suffer from stress, anxiety and depression in the post-disaster period. However, the level of the psychological con-

Table 3. Level of psychological vulnerability of the studied community.

\begin{tabular}{|c|c|c|c|c|c|}
\hline Sample station & Respondent (gender) & Sample (number) & PTSD & $\begin{array}{l}\text { Mean } \\
\text { GAD }\end{array}$ & MDD \\
\hline North - first stations & Both & 18 & 0.69 & 0.72 & 0.55 \\
\hline (Points adjacent to the river) & Male & 9 & 0.68 & 0.67 & 0.53 \\
\hline$(1,5,9,21,25,29,33,41,45)$ & Female & 9 & 0.71 & 0.78 & 0.57 \\
\hline $\begin{array}{l}\text { North - second stations } \\
\text { (Points } 1 \text { km from the river) } \\
\text { (1a, 5a, 9a, 21a, 25a, 29a, 33a, 41a, 45a) }\end{array}$ & $\begin{array}{l}\text { Both } \\
\text { Male } \\
\text { Female }\end{array}$ & $\begin{array}{l}18 \\
9 \\
9\end{array}$ & $\begin{array}{l}0.56 \\
0.53 \\
0.58\end{array}$ & $\begin{array}{l}0.54 \\
0.49 \\
0.59\end{array}$ & $\begin{array}{l}0.40 \\
0.39 \\
0.42\end{array}$ \\
\hline $\begin{array}{l}\text { North - third stations } \\
\text { (Points } 2 \mathrm{~km} \text { from the river) } \\
\text { (1b, 5b, 9b, 21b, 25b, 29b, 33b, 41b, 45b) }\end{array}$ & $\begin{array}{l}\text { Both } \\
\text { Male } \\
\text { Female }\end{array}$ & $\begin{array}{l}18 \\
9 \\
9\end{array}$ & $\begin{array}{l}0.50 \\
0.48 \\
0.52\end{array}$ & $\begin{array}{l}0.47 \\
0.42 \\
0.51\end{array}$ & $\begin{array}{l}0.35 \\
0.33 \\
0.37\end{array}$ \\
\hline $\begin{array}{l}\text { South - first stations } \\
\text { (Points adjacent to the river) } \\
(1.1,5.1,9.1,13.1,17.1,21.1,25.1,37.1,41.1,45.1)\end{array}$ & $\begin{array}{l}\text { Both } \\
\text { Male } \\
\text { Female }\end{array}$ & $\begin{array}{l}20 \\
10 \\
10\end{array}$ & $\begin{array}{l}0.65 \\
0.65 \\
0.66\end{array}$ & $\begin{array}{l}0.72 \\
0.68 \\
0.76\end{array}$ & $\begin{array}{l}0.48 \\
0.47 \\
0.49\end{array}$ \\
\hline $\begin{array}{l}\text { South - second stations } \\
\text { (Points } 1 \mathrm{~km} \text { from the river) } \\
\text { (1.1a, 5.1a, 9.1a, 13.1a, 17.1a, 21.1a, 25.1a, 37.1a, 41.1a, 45.1a) }\end{array}$ & $\begin{array}{l}\text { Both } \\
\text { Male } \\
\text { Female }\end{array}$ & $\begin{array}{l}16 \\
8 \\
8\end{array}$ & $\begin{array}{l}0.46 \\
0.44 \\
0.48\end{array}$ & $\begin{array}{l}0.45 \\
0.42 \\
0.48\end{array}$ & $\begin{array}{l}0.31 \\
0.29 \\
0.34\end{array}$ \\
\hline $\begin{array}{l}\text { South - third stations } \\
\text { (Points } 2 \text { km from the river) } \\
\text { (1.1b, 5.1b, 9.1b, 13.1b, 17.1b, 21.1b, 25.1b, 37.1b, 41.1b, 45.1b) }\end{array}$ & $\begin{array}{l}\text { Both } \\
\text { Male } \\
\text { Female }\end{array}$ & $\begin{array}{l}16 \\
8 \\
8\end{array}$ & $\begin{array}{l}0.34 \\
0.33 \\
0.36\end{array}$ & $\begin{array}{l}0.35 \\
0.31 \\
0.39\end{array}$ & $\begin{array}{l}0.22 \\
0.19 \\
0.24\end{array}$ \\
\hline
\end{tabular}

PTSD, posttraumatic stress disorder; GAD, generalized anxiety disorder; MDD, major depressive disorder.

Table 4. Pearson correlation.

\begin{tabular}{lccc} 
Statistic & PISD & GAD & MDD \\
PTSD & 1 & $0.943^{* *}$ & $0.935^{* *}$ \\
GAD & $0.943^{* *}$ & 1 & $0.950^{* *}$ \\
\hline MDD & $0.935^{* *}$ & $0.950^{* *}$ & 1 \\
\hline
\end{tabular}

PTSD, posttraumatic stress disorder; GAD, generalized anxiety disorder; MDD, major depressive disorder. ${ }^{* *}$ Correlation significant at the 0.01 level.

Table 5. Linear regression analysis of the relationship between the psychological states in the study community.

\begin{tabular}{lccccccccc} 
Variables & \multicolumn{2}{c}{ MIDD } & & & & GAD & \\
& $\beta$ & $95 \% \mathrm{CI}$ & P-value & SE & $\beta$ & $95 \% \mathrm{CI}$ & P-value & SE \\
PTSD & 0.935 & $0.726,0.893$ & 0.000 & 0.533 & 0.943 & $0.957,1.161$ & 0.000 & 0.647 \\
\hline
\end{tabular}

MDD, major depressive disorder (dependent variable); GAD, generalized anxiety disorder (dependent variable); $\beta$, coefficient; $95 \%$ CI, confidence interval; SE= standard error; PTSD, posttraumatic stress disorder (predictor variable). 
ditions instigated is not in the same in every place affected by the disaster as the likelihood of being psychologically injured by a disaster varies with space and time. Thus, people from different places and environmental settings face the same disaster differently. PTSD is the most commonly studied and probably the most frequent and debilitating psychological disorder that occurs after traumatic events and natural disasters (North et al., 1999; Norris et al., 2002). It has been found that the people of the study area showed moderate to extreme stress after the flood. With regard to PTSD, several cases from north-western Darbasta Union seemed to be different than others. We found that the area situated near and in between three ox-bow lakes (Figure 7) was particularly badly affected, with the whole area eventually flooded with the rise in water level. People there developed extreme and severe level of PTSD both near and far away from the river. On the other hand, Sapmara Union which is a part of the Barind Tract (the largest pleistocene terrace of old alluvium in the country) where floods do not touch some parts, people showed only moderate levels of PTSD as damage was indirect and mainly concerned their agricultural land near the river. However, people there were under stress for affected close relatives in other areas touched by the flood, e.g., the channel flowing through Gobindaganj Pourashava, which commonly overflows and therefore caused severe PTSD in the commu- nity near the river in 2017. Another problem was faced by people from south-eastern Taluk Kanupur and north-western Rakhal Buruz Unions because of river loops and ox-bow lake problems, which led to severe-level PTSD. Thus, environmental settings of that area significantly influenced the PTSD pattern. In addition, the generalized picture of PTSD in the study area indicated that homogeneous environmental settings might lead a higher level of PTSD near the river, while lower levels of PTSD were found far away from the river, while it can also be said that some heterogeneous geographic settings (presence of ox-bow lakes, river loops, etc.) changed the pattern of PTSD.

Another psychological sequela of disasters is general anxiety, which is considered as the sense of dread or fright that something outrageous will happen. It is an emotional response to one or more stimuli that can be internal or external to the person and can be the result of any social situation, both general and space-specific. GAD is mostly less studied in communities affected by disasters, e.g., Norris et al. (2002) reported that very limited studies have been conducted on death anxiety, various phobia and panic disorders which are very common in affected communities, and this situation has not changed.

Just like PTSD, severe-level GAD was found near the river, while milder forms of this mental disorder were found far away

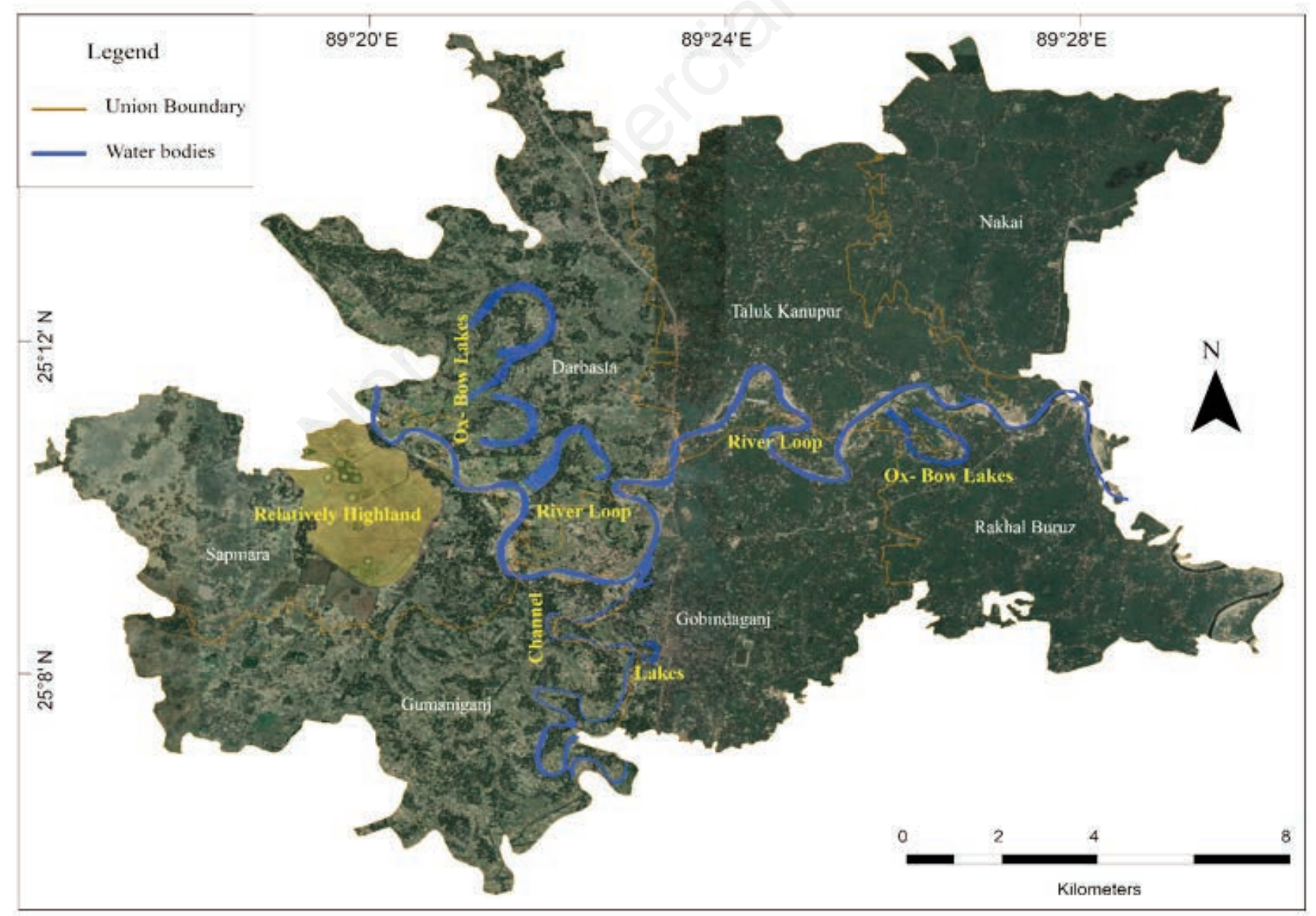

Figure 7. Major geographic variables and their associations in the study area. 
from the river. We found that the presence of several geographic variables in the study area as well as PTSD caused varies levels of GAD in the communities. Because of the continuous rise in water level and the position of their settlements relative to the river, the people from south-eastern Taluk Kanupur and north-western Rakhal Buruz developed moderate levels of GAD and people from Darbasta and Gobindaganj severe levels of this disorder.

Depression is the second most commonly studied post-disaster mental health condition (Norris, et al., 2002); however, owing to its large burden in the general population, it may be even more common than PTSD, currently believed to be the most prevalent post-disaster disorder. Clinical depression is a disorder that is sustained over time and affects mood in a general way. The present study community showed normal to moderate major depressions after the 2017 floods, but no severe major depression was noted. In the post-disaster period the study community also faced depressive disorder. Just like PTSD and GAD, the communities near the river showed moderate-level MDD. Darbasta Union and Gobindaganj Community showed moderate-level MDD, while other areas showed mild-level MDD along with the geographic variability along with their internal and external coping mechanism. Damages due to physical settings varied and the external help, recovery procedures, community resilience played vital role in the development of the depressive disorder. It was difficult, sometimes impossible, to find a pattern in a single administrative unit because the impact of hazards does not follow administrative boundaries. However, the understanding of hazard exposure impacts becomes more meaningful when a place is perceived as geographic space. Considering all the geographic variables in the study area, we found a general clustering pattern of psychological vulnerabilities. Generally, higher levels of psychological vulnerability occurred near the river, while a relatively medium level of psychological vulnerability was found $1 \mathrm{~km}$ from the river and lower-level psychological vulnerabilities $2 \mathrm{~km}$ away (Figure 5). In addition, there was a significant variation in psychological vulnerability between the areas north and south of the river.

Hazards like flood have some geographical extend and factors. Generally, geographical factors like elevation of an area, landforms, soil types, climate and association of other geographical features greatly influence flooding. But the rive location, ox-bow lakes, channels, settlements as well as their association are examples leading to vulnerability by flooding causing the community to be mentally vulnerable during and aftermath of such events. Also, these variables play a significant role when attempting to determine the spatial pattern of psychological vulnerability. This kind of vulnerability is high in communities near the river and gradually decreases with distance from it. In Bangladesh, disaster management is generally focused on sustainable development, proper utilizations of resources, mass awareness, etc.

In this study the major attention was given to the spatial settings and physical variables of environment and there was a huge scope to consider the social capital, response pattern as well as the community resilience. In future research, community resilience and social capital will be observed to understand this spatial pattern of psychological vulnerability.

\section{Conclusions}

This research is based on the interest of the geographic variability of 2017 flood related mental health and psychological vul- nerability at the individual-level unit of analysis. Recovery processes after hazardous events are longwinded in Bangladesh due to lack of practical knowledge about geographic variability although such knowledge might help to execute recovery initiatives. In addition, mental health is relatively ignored during disaster management initiatives. If there is enough research and focus on the geographic variability of post disaster mental health that might help the disaster management procedure to focus on where help should be given and also indicate future direction of disaster management policy.

\section{References}

Agaibi CE, Wilson JP, 2005. Trauma, PTSD, and resilience: a review of the literature. Trauma Violence Abuse 6:195-216.

Alderman K, Turner LR, Tong S, 2012. Floods and human health: a systematic review. Environ Int 47:37-47.

American Psychological Association, 2018. PTSD assessment instruments. Available from: https:/www.apa.org/ptsd-guideline/assessment/

ADB, 2019. Recent significant disaster in the Asia and Pacific Region. Available from: https://www.adb.org/news/infographics/recent-significant-disasters-asia-and-pacific-region

Bass B, 2015. What is spatial pattern in geography. Available from: https://www.quora.com/What-is-a-spatial-pattern-in-geography

Blevins CA, Weathers FW, Davis MT, Witte TK, Domino JL, 2015. The posttraumatic stress disorder checklist for DSM-5 (PCL-5): development and initial psychometric evaluation. J Trauma Stress 28:489-98.

Curtis A, Mills JW, Leitner M, 2007. Katrina and vulnerability: the geography of stress. J Health Care Poor Underserved 18:315-30.

Davies R, 2017. Bangladesh-floods worsen as death toll rises. Available from: http://floodlist.com/asia/bangladesh-floodsworsen-as-death-toll-rises

DhakaTribune, 2017. Flooding worsens in three districts. Available from: https://www.dhakatribune.com/bangladesh/ nation/ 2017/08/20/flood-situation-worsens-three-districts/

DiMaggio C, Galea S, Emch M, 2010. Spatial proximity and the risk of psychopathology after a terrorist attack. Psychiatry Res 176:55-61.

ESRI, 2005. How Spatial Autocorrelation: Moran's I (spatial statistics) works. Available from: http://resources.esri.com/ help/9.3/arcgisengine/java/gp_toolref/spatial_statistics_tools/h ow_spatial_autocorrelation_colon_moran_s_i_spatial_statistics_works.h.htm

Fewtrell L, Kay D, 2007. An attempt to quantify the health impacts of flooding in the UK using an urban case study. Public Health 122:446-51.

Freedy JR, Simpson WM, 2007. Disaster-related physical and mental health: a role for the family physician. Am Fam Physician 15;75:841-6.

Fung HW, Chan C, Lee CY, Ross CA, 2019. Using the post-traumatic stress disorder (PTSD) checklist for DSM-5 to screen for PTSD in the Chinese context: a pilot study in a psychiatric sample. J Evid Base Soc Work 16:634-51.

Gaillard JC, Walters V, Rickerby M, Shi, Y, 2019. Persistent precarity and the disaster of everyday life: homeless people's experiences of natural and other hazards. Int J Disaster Risk Sci 10:332-42.

Ginexi EM, Weihs K, Simmens SJ, Hoyt DR, 2000 Natural disaster 
and depression: a prospective investigation of reactions to the 1993 Midwest floods. Am J Community Psychol 28:495-518.

Goldmann E, Galea S, 2014. Mental health consequences of disasters. Annu Rev Public Health 35:169-83.

Gonzales J, 2019. Areas in Southeast Asia most affected by natural disaster. Available from: https://daydreaminginparadise. com/areas-in-southeast-asia-most-affected-by-natural-disasters/

Gruebner O, Lowe SR, Sampson L, Galea S, 2015. The geography of post disaster mental health: spatial patterning of psychological vulnerability and resilience factors in New York city after Hurricane Sandy. Int J Health Geogr 14:16.

Ibrahim H, Ertl V, Catani C, Ismail AA, Neuner F, 2018. The validity of posttraumatic stress disorder checklist for DSM-5 (PCL5) as screening instrument with Kurdish and Arab displaced populations living in the Kurdistan region of Iraq. BMC Psychiatry 18:259.

Jankowski K, 2016. The effect of disaster on people with severe mental illness. Available from: https:/www.ptsd.va.gov/professional/trauma/disaster-terrorism/effects-disaster-mental-illness.asp

Kar N, Bastia BK, 2006. Post-traumatic stress disorder, depression and generalized anxiety disorder in adolescents after a natural disaster: a study of comorbidity. Clin Pract Epidemiol Ment Health 2:17.

Kim SC, Plumb R, Gredig QN, Rankin L, Taylor B, 2008. Medium-term post-Katrina health sequelae among New Orleans residents: predictors of poor mental and physical health. J Clin Nurs 17:2335-42.

Kroenke K, Spitzer R, Williams JBW, 2001. The PHQ-9 validity of a brief depression severity measure. J Gen Intern Med 16:606-13.

Kroenke K, Spitzer R, Williams JBW, Monahan PO, Lowe B, 2007. Anxiety disorders in primary care: prevalence, impairment, comorbidity, and detection. Ann Intern Med 146:317-25.

Maghrabi K, 2012. Impact of flood disaster on the mental health of residents in the Eastern Region of Jeddah Governorate, 2010: a study in medical geography. Life Sci J 9:95-110.

Magowan N, 2018. PCL-5 Post traumatic stress disorder (PTSD) assessment checklist. Available from: https:/www.manchester-psychotherapy.co.uk/anxiety-disorders-treatmentcbt/emotional-and-psychological-trauma-ptsd-treatmentmanchester/ptsd-assessment-test-pcl-5-outcome-measure/

Makwana N, 2019. Disaster and its impact on mental health: a narrative review. J Family Med Prim Care 8:3090-95.

Maroufizadeh S, Omani-Samani R, Almasi-Hashiani A, Amini P, Sepidarkish M, 2019. The reliability and validity of the patient health questionnaire-9 (PHQ-9) and PHQ-2 in patients with infertility. Reprod Health 16:137.

Marshall C, Rossman GB, 2010. Designing qualitative research. Sage Publication, Thousand Oaks, CA, USA.

McFarlane AC, Williams R, 2012. Mental health services required after disasters: learning from the lasting effects of disasters. Depress Res and Treat 2012:970194.

Mental Health America, 2018. Coping with disaster. Available from: http://www.mentalhealthamerica.net/conditions/copingdisaster

National Center for PTSD, 2019. PTSD Checklist for DSM-5 (PCL-5). Available from: https://www.ptsd.va.gov/profession$\mathrm{al} /$ assessment/adult-sr/ptsd-checklist.asp

National Disaster Reduction Center of China, 2017. Monsoon Flood, Bangladesh. Available from: https://reliefweb.int/sites/
reliefweb.int/files/resources/72\%20hrs-Bangladesh Flood_Version1_Final\%2008212017.pdf

Niekerk DV, 2011. Introduction to disaster risk reduction. Available from: https://www.preventionweb.net/files/ 26081_kp1concepdisasterrisk1.pdf

NIRAPAD, 2017. Overview of flood; August 2017. Available from: https://reliefweb.int/sites/ reliefweb.int/files/resources/ Situation_Report $\% 20$ of $\% 20$ Flood $\% 20$ Updated $\% 20$ on $\% 20 \mathrm{~A}$ ugust_22\%2C\%202017.pdf

Davies R, 2017. Bangladesh-floods worsen as death toll rises. Available from: http://floodlist.com/asia/bangladesh-floodsworsen-as-death-toll-rises

Norris FH, Friedman MJ, Watson PJ, Byrne CM, Diaz E, Kaniasty K, 2002. 60000 Disaster victims speak: part I. An empirical review of the empirical literature. Psychiatry 65:207-39.

North CS, Nixon SJ, Shariat S, 1999. Psychiatric disorders among survivors of the Oklahoma City bombing. JAMA 282:755-62.

Osório FL, Silva TDA, Santos RG, Chagas MHN, Chagas NMS, Sanches RF, Crippa JAS, 2016. Posttraumatic stress disorder checklist for DSM-5 (PCL-5): transcultural adaptation of the Brazilian version. Arch Clin Psychiatr 44:10-9.

Prothom Alo, 2017. Banbhasi Jibon. Available from: http://www.prothomalo.com/floods

Rancans E, Trapencieris M, Ivanovs R, Vrublevska J, 2018. Validity of the PHQ-9 and PHQ-2 to screen for depression in nationwide primary care population in Latvia. Ann Gen Psychiatry 17:33.

Rathore JS, Jehi LE, Fan Y, Patel SI, Foldvary-Schaefer N, Ramirez MJ, Busch RM, Obuchowski NA, Tesar GE, 2014. Validation of the patient health questionnaire-9 (PHQ-9) for depression screening in adults with epilepsy. Epilepsy Behav 37:215-20.

Rodriguez-Llanes JM, Vos F, Guha-Sapir D, 2013. Measuring psychological resilience to disasters: are evidence-based indicators an achievable goal. Environ Health 12:115.

Tobler WR, 1970. A computer movie simulating urban growth in the Detroit Region. Econ Geogr 46:234-40.

Trochim WMK, 2018. Sampling. Available from: https://conjointly.com/kb/probability-sampling/

United Nations International Strategy for Disaster Reduction (UNISDR), 2009. 2009 UNISDR terminology on disaster reduction. Available from: https://www.unisdr.org/files/7817_ UNISDRTerminologyEnglish.pdf

Ursano RJ, Cerise FP, DeMartino R, Reissman DB, Shear, MK, 2006. The impact of disasters and their aftermath on mental health. J Clin Psychiatry 67:7-14.

Usman RA, Olorunfemi FB, Awotayo GP, Tunde AM, Usman BA, 2013. Disaster risk management and social impact assessment: understanding preparedness, response and recovery in community projects. In: S. Silvern and S. Young (Eds.), Chapter 10: Environmental Change and Sustainability. IntechOpen Book Series, pp. 269-274.

Weather FS, Litz BT, Keane TM, Palmieri PA, Marx BP, Schnurr PP, 2013. The PTSD Checklist for DSM-5. Available from: https://www.ptsd.va.gov/professional/assessment/adultsr/ptsd-checklist.asp

Weiss RS, 1995. Learning from strangers: the art and method of qualitative interview studies. Simon and Schuster, Canada, pp. 33.

Williams N, 2014. The GAD-7 questionnaire. Occupat Med 64:224.

Wisner B, Blaikie P, Cannon T, Davis I, 2004. At risk: natural haz- 
ards, people's vulnerability and disasters. Routledge, New York, NY, USA, 5 pp.

World Health Organization, 2002. Disasters and emergencies. Available from: http://apps.who.int/disasters/repo/7656.pdf

World Health Organization, 2019. Disaster and mental health.
Available from: http://www.searo.who.int/bangladesh/disastersandmentalhealth/en/

World Health Organization, 2020. Environmental health in emergencies. Available from: https://www.who.int/environmental_health_emergencies/natural_events/en/ 